\title{
El dictamen de Letrado en las acciones de lás Corporaciones locales
}

\author{
por \\ LUIS ARCE MONZON \\ Secretario de r. ${ }^{\text {a }}$ categoría de Administración local.
}

Sumario: I. Introducción.-II. La normatividad positiva vigente.-III. AnteCEDENTES Legales.-IV. La juRisprudencia del Tribunal Supremo.-V. Juicio C.Rítico: 1. Alcance de la expresión «ejercicio de acciones». 2. El dictamen del Secretario-Letrado.-VI. Conclusión.

\section{INTRODUCCION}

La exigencia del dictamen de Letrado, que debe preceder a la adopción de acuerdos de las Corporaciones locales para el ejercicio de acciones en defensa de sus bienes y derechos, en los términos que se regula en nuestra Ley, nos resulta extraña e injustificada. Nos atrevemos a creer que de modo semejante piensan no pocos de los Secretarios de Administración local, profesionales de esta rama del Derecho público.

De un modo particular nos ha movido a expresar nuestra opinión en la materia un texto de la sentencia del Tribunal Supremo, Sala Tercera, de fecha 6 de febrero de 1967, que dice así: «En cuanto a la exigencia de dictamen de Letrado, como previo a toda procesal presencia de una Corporación local, conviene evitar la confusión entre la indiscutible necesidad del previo dictamen para formular una demanda y la ya no del todo modo requerible para pura y simplemente defenderse frente a una reclamación, una demanda o un recurso, pues la actitud de atacante es voluntaria, mientras que la del que se defiende es obligada». Tal redacción, que oscila entre la timidez y el circunloquio, es exponente de algo que requiere mayor seguridad y precisión.

\section{LA NORMATIVIDAD POSITIVA VIGENTE}

Por razón de buena sistemática es conveniente repetir ahora los preceptos de nuestro Derecho positivo que se refieren a este problema del dictamen previo de Letrado. 
El artículo 370 de la Ley de Régimen local, texto refundido de 24 de junio de 1955, dice así: «Las Corporaciones locales tienen la obligación de ejercer las acciones necesarias para la defensa de sus bienes y derechos. El acuerdo correspondiente deberá ir precedido del dictamen de un Letrado».

En el artículo 338 del Reglamento de Organización, Funcionamiento y Régimen jurídico de las Corporaciones locales de 17 de mayo de 1952, se dispone: «1. Las Corporaciones locales tienen el deber inexcusable de defender sus bienes y derechos mediante el ejercicio de las pertinentes acciones y previo dictamen de un Letrado. 2. Cuando éste fuere opuesto al ejercicio de la acción podrá recabar otros o renunciar a entablarlos, y en cualquier caso, promoverla sin someterse a ninguno de ellos. 3. Aparte de los informes jurídicos que emita el Secretario, los Letrados asesores de la Corporación pertenecientes a su plantilla de funcionarios tendrán la obligación de informar, ateniéndose a lo previsto en el artículo 286. 4. Si la Corporación no tuviere Letrados, podrá solicitar el dictamen de Abogado que figure inscrito en el Colegio correspondiente y satisfaga contribución industrial».

$\mathrm{Y}$ en relación con los preceptos transcritos en los precedentes párrafos, es de recordar el artículo 57 de la Ley reguladora de la Jurisdicción Contencioso-administrativa, de 27 de diciembre de 1956, en virtud del cual las Corporaciones locales acompañarán al escrito de interposición del recurso «el documento que acredite el cumplimiento de las formalidades que para entablar demandas» exijan sus leyes especiales. Entre tales requisitos, sin duda, está comprendido el dictamen previo de Letrado.

\section{ANTECEDENTES LEGALES}

Muy someramente haremos mención a los antecedentes legales en este trámite del dictamen previo de Letrado, en la medida en que nos ilustran respecto a la evolución experimentada en nuestro Derecho.

En el artículo 86 de la Ley municipal de 2 de octubre de 1877 se exigía ya el «previo dictamen conforme de dos Letrados» para que los Ayuntamientos entablen pleitos. No obstante, no se necesitaba dictamen de Letrado para ejercitar interdictos de retener, de recobrar, de obra nueva o vieja «ni para seguir los pleitos en que el Ayuntamiento fuese demandados. Se limitaba, pues, la exigencia del dictamen de Letrado a los casos de pleitos ante los Tribunales de Justicia.

El artículo 156 del Estatuto municipal de 8 de marzo de 1924 disponía que «Para ejercitar acciones civiles, contencioso-administrativas, penales y administrativas, al acuerdo del Ayuntamiento Pleno deberá preceder dictamen de una o dos Letrados, según la importancia del caso». El artículo $6 .^{\circ}$ del Reglamento de Procedimiento en materia municipal, de 23 de agosto de 1924, puntualizó que al ejercicio de acciones no era obstáculo que los dictámenes no fuesen favorables ni que fuesen disconformes entre sí. El Estatuto amplió, por tanto, el trámite de dic- 
tamen de Letrado a las acciones administrativas más allá, pues, de las de carácter judicial.

El Estatuto provincial de 20 de marzo de 1925, que en su artículo 108 encomendaba a las Diputaciones el ejercicio de acciones jurídicas y extrajudiciales, no exigió, para ello, el trámite de dictamen previo de Letrado.

En el artículo 207 de la Ley municipal de 31 de octubre de 1935 se decía: «Es facultad discrecional de las Corporaciones municipales el ejercicio de acciones judiciales, que irá precedido en todo caso del informe de dos Letradios. Cuando tuviesen un Letrado asesor, éste será uno de los informantes; cuando hubiese varios Letrados asesores, la Corporación designará de entre ellos a los que hayan de informar». Con precisión terminológica, que evitaba confusiones, la Ley de 1935 se refería expresamente a las «acciones judiciales».

\section{LA JURISPRUDENCIA DEL TRIBUNAL SUPREMO}

La gama de sentencias del Tribunal Supremo, en cuanto al problema del dictamen de Letrado en el ejercicio de acciones por las Corporaciones locales, es variada y contiene criterios y soluciones para gustos varios.

Citaremos algunas de las sentencias que se nos of recen como las más expresivas de la apuntada variedad de criterios y de las distintas cuestiones que plantea nuestro tema:

No es necesario dictamen previo de Letrado para interponer recursos administrativos: "Que tampoco puede darse acogida al motivo de im. pugnación basado en la falta de dictamen de Letrado previo a la formalización de la alzada, pues el artículo 370 de la Ley de Régimen local de 24 de de junio de 1955 y su concordante el 338 del Reglamento de Organización, Funcionamiento y Régimen jurídico de las Corporaciones locales de 17 de mayo de 1952, que exigen dicho trámite, lo refieren concretamente al ejercicio de acciones y no a la interposición de carácter administrativo» (Sentencia de 4 de mayo de 1961).

Es necesario el dictamen previo de Letrado para interponer recursos administrativos: "Que al escrito de interposición del recurso de reposición... por el Ayuntamiento de... sólo se acompañó poder para litigar..., sin que aparezca que con el referido documento se acreditase poseer además el correspondiente acuerdo municipal y el dictamen de un Letrado exigidos por la Ley municipal vigente... que efectivamente la actual Ley de Régimen local de 24 de junio de 1955 recogiendo el antecedente de los textos legales anteriores condiciona la actividad jurisdiccional de las Corporaciones locales a que el acuerdo correspondiente, para el ejercicio de las acciones necesarias en defensa de sus bienes y derechos, "vaya precedido del dictamen de un Letrado (art. 370)... los textos citados sancionan un concepto mucho más amplio, que comprende incluso los recursos administrativos»... porque el defecto advertido le falta acreditar el dictamen previo del Letrado y no es subsanable, 
puesto que la resolución administrativa tomada en tal sentido se apoya, precisamente para desestimar la reposición interpuesta, con justo fundamento en tal defecto... es obligado concluir que la Orden de 30 de mayo de 1960 recuerda, al declarar inadmisible el recurso de reposición interpuesto por la Corporación de... por no haberse acreditado los dos requisitos de que queda hecha mención, se ajustó a lo dispuesto en la Ley (Sentencia de 28 de septiembre de 1961);... «que los acuerdos que tomen las Corporaciones locales para el ejercicio de las acciones necesarias a la defensa de sus bienes y derechos, han de ir precedidos del dictamen mencionado, habiendo mantenido esta Sala en la sentencia de 9 de noviembre de 1962 la necesidad de tal requisito, incluso para promover los recursos administrativos» (Sentencia de 23 de enero de 1964).

Es necesario el dictamen de Letrado para interponer recurso de apelación: ... «y que el artículo 370 del mismo texto legal (Ley de Régimen local)... establece que los acuerdos correspondientes para ejercitar las acciones necesarias para la defensa de sus bienes y derechos deberá ir precedido del dictamen de Letrado; ahora bien, de la aplicación de los antedichos preceptos al caso contemplado en esta apelación, aparece patente que no se acredita en modo alguno por el Ayuntamiento apelainte el cumplimiento de las mentadas disposiciones... no se acredita de ninguna manera... ni que el Ayuntamiento Pleno haya acordado, en forma legal, la interposición del presente recurso de apelación, ni tampoco que el referido acuerdo haya sido precedido del necesario dictamen de Letrado, requisitos ambos exigidos por la Ley mencionada, lo que trae como consecuencia obligada la inadmisibilidad del presente recurso de apelación» (Sentencia de 29 de mayo de 1965).

No es necesario el dictamen de Letrado cuando las Corporaciones locales interponen recursos de apelación: «que alegadas... la inadmisibilidad de esta apelación por no acompañar el Ayuntamiento recurrente el dictamen de Letrado que exige el artículo 370 de la Ley de Régimen local, texto refundido de 24 de junio de 1955, para el ejercicio de acciones por los entes locales... tampoco se estaría exactamente en el supuesto legal del ejercicio inicial de acción, sino que el Ayuntamiento actúa en defensa de la ejercitada contra él y en consecuencia de todo procede desestimar esta petición de inadmisibilidad» (Sentencia de 30 de junio de 1967) ; ... «que planteado por la representación del apelado la existencia de un defecto básico a su juicio para que pueda prosperar el recurso de apelación. interpuesto por el Ayuntamiento... dado lo dispuesto en el artículo 370 de la Ley de Régimen local... que exigen para el ejercicio de cualquier acción necesaria para la defensa de los bienes y derechos municipales, que el acuerdo correspondiente vaya precedido del dictamen de un Letrado... es evidente que los recursos que contra la sentencia dictada en el pleito tramitado por ser una consecuencia del mismo no puede estimarse coma una nueva acción que determine la necesidad de someter a un dictamen de Letrado la procedencia del recurso, sobre todo si como en el caso presente se trata de mantener la procedencia de unos acuerdos municipales dictados por la Corporación municipal dentro de sus atribuciones, sometiéndose en esta 
vía jurisdiccional únicamente la cuestión de si los mismos han contrariado o no el ordenamiento jurídico establecido en la materia, lo que lleva consigo la procedencia de desestimar la petición que se formula de que se declare no haber lugar al recurso de apelación interpuesto por la Corporación municipal» (Sentencia de 25 de noviembre de 1965).

No se exige el dictamen de Letrado para la defensa de las Corporaciones cuando son demandados: «El dictamen de Letrado requerido en el artículo 370 de la Ley de Régimen local y en el 338 del Reglamento de Régimen jurídico de las Corporaciones locales para el ejercicio de acciones... conviene dejar sentado que ésta (la exigibilidad del dictamen) la establecen los citados artículos para ejercitar las acciones o promoverlas, cual puntualiza el 338 , párrafo $22^{\circ}$, mas no para defenderse de las dirigidas contra el ente» (Sentencia de 19 de diciembre de 1964). En el mismo sentido, sentencias de 29 de enero y 3 de octubre de 1966.

Se cumple el requisito de dictamen previa con el emitido por Secretario-Letrado: ... «debe de entenderse que aunque el funcionario municipal informante no pertenezca a la plantilla con el estricto y único concepto de Letrado asesor de la Corporación, su título de Licenciado en Derecho, cuando lo tenga, le habilita para la emisión del aludido dictamen... y en un Ayuntamiento rural... en el que el Secretario es Licenciado en Derecho, ningún precepto se opone a que, como Letrad'o que es, emita el dictamen referido... la condición de Letrado en la acepción de esta palabra equivalente a Licenciado en Derecho; por todo lo cual debe entenderse cumplido por el Ayuntamiento... el requisito del dictamen exigido por el artículo 370 de la Ley» (Sentencia de 12 de abril de 1958).

\section{JUICIO CRITICO}

La evolución legislativa y la jurisprudencia del Tribunal Supremo, que hemos reseñado, nos conducen a centrar nuestra opinión en torno a las principales cuestiones que plantea el problema del dictamen de Letrado previo al ejercicio de acciones por las Corporaciones locales, y que sistematizamos del siguiente modo:

1. Alcance de la expresión «ejercicio de acciones».

2. El dictamen del Secretario-Letrado.

\section{Alcance de la expresión «ejercicio de acciones».}

El concepto de acción, dentro del campo jurídico, al que lógicamente hemos de limitarnos, es relativo, influenciado por razones históricas y políticas. Sin embargo, en general, las doctrinas modernas consideran la acción como el derecho de promover e iniciar el proceso jurisdiccional del Estado, es decir, la actividad de los Tribunales que administran la justicia. La jurisprudencia de nuestro Tribunal Supremo así lo ha entendido al referirse a la acción que «en su aspecto procesal es 
como facultad o derecho de pedir a un órgano jurisdiccional del Estado la actuación de una voluntad de la Ley para obtener un bien determinado» (Sentencia de 6 de noviembre de 1941).

El Diccionario de la Real Academia Española de la Lengua define la acción en el mismo sentido a que nos hemos referido, en los siguientes términos: «Derecho que se tiene a pedir alguna cosa en juicio»; y «modo legal de ejecutar el mismo derecho».

En nuestro Derecho positivo y en la Ley Orgánica del Estado, de 10 de enero de 1967, con rango de Ley Fundamental, son de citar los siguientes preceptos, que configuran también la acción como derecho de los españoles a la protección de los Tribunales de Justicia, a los que incumbe la función jurisdiccional de juzgar:

«Artículo 30. Todos los españoles tendrán libre acceso a los Tribunales. La Justicia será gratuita para quienes carezcan de medios económicos.

Artículo 31. La función jurisdiccional, juzgando y haciendo ejecutar lo juzgado, en los juicios civiles, penales, contencioso-administrativos, laborales y demás que establezcan las leyes, corresponde exclusivamente a los Juzgados y Tribunales determinados en la Ley orgánica de la Justicia, según su diversa competencia».

Por lo dicho anteriormente llegamos a la conclusión de que el ejercicio de acciones a que se refiere el artículo 370 de la Ley de Régimen local, y que ha de ir precedido del dictamen de un Letrado, se condiciona, limita y perfila, en nuestra opinión e interpretación, en los siguientes términos:

a) Las acciones son las que se ejercitan, de modo activo, por las Corporaciones locales, ante los Tribunales de Justicia de las distintas jurisdicciones.

b) Cuando las Corporaciones locales son demandadas, propiamente no ejercitan una acción, sino han de defenderse en el proceso frente a la que se ejercita contra ellas.

Por tanto, nos situamos en la postura de la Ley municipal de 1935, que con precisión digna de encomio se refería solamente «al ejercicio dé acciones judiciales», es decir, ante los Tribunales de Justicia, como único caso en el que se exigía dictamen de Letrados.

c) La interposición de recursos por las Corporaciones locales frente a sentencias de los Tribunales de Justicia, ante otros Tribunales superiores, no ha de entenderse, en sentido estricto, como ejercicio de acciones que requieran el dictamen de Letrado, por cuanto la acción se inició en el proceso del Tribunal inferior, precedida de dictamen. Los recursos subsiguientes no son sino fases de la misma acción y proceso.

Por el contrario, estimamos que la extensión del trámite del citado dictamen de Letrado a los supuestos de recursos administrativos interpuestos por Corporaciones locales, que se sostiene en algunas sentencias del Tribunal Supremo, va más allá de la Ley, entorpece la agilidad de la Administración local e incluso merma la competencia y autonomía de sus organismos, a la hora de ejercitar por una Corporación local un 
recurso de reposición o de alzada, incluso en un expediente sencillo o de escasa importancia (por ejemplo, contra una resolución de la Mutualidad Nacional de Previsión de la Administración Local, que motive un pago de 13 pesetas por un Ayuntamiento como pensión graciable de un funcionario).

\section{El dictamen del Secretario-Letrado.}

La otra cuestión fundamental que planteamos se refiere a si resulta justificada la exigencia de dictamen de Letrado previo al ejercicio de acciones por las Corporaciones locales, en el supuesto de que exista en la misma Secretario que sea Letrado o Licenciado en Derecho.

Encontramos injustificada la inercia legislativa que ha venido arrastrando el trámite o requisito del dictamen de Letrado, que comentamos.

Quizá tuviese razón de ser en la Ley municipal de 1877 en la medida en que su artículo 123, y en cuanto a la formación y nivel cultural de los Secretarios de Ayuntamiento, se contentaba con exigir que era necesario poseer «los conocimientos de la instrucción primaria». Pero hoy son otros los aires que corren. La posesión del título de Licenciado en Derecho, exigido para el desempeño del cargo de Secretario de primera categoría de Administración local, la concurrencia del mismo título en buena parte de Secretarios de segunda y tercera categoría, y la aspiración e incuestionable necesidad de que el Cuerpo de Secretarios esté constituido, en todo caso, por Licenciados en Derecho, obliga a reconsiderar el problema del dictamen de Letrado.

Nuestra opinión, en definitiva, es la de que cuando el Secretario de la Corporación local ostente el título de Licenciado en Derecho, el dictamen de Letrado requerido por el artículo 370 de la Ley de Régimen local queda cumplimentado con el que emita aquel funcionario. Por las siguientes razones:

a) La primerísima y más definitiva, por la condición y funciones de asesor jurídico que compete al Secretario, de conformidad con lo que disponen los artículos 341 y 413 de la vigente Ley de Régimen local, el artículo 143 del Reglamento de Funcionarios de Administración local de 30 de mayo de 1952 y el artículo 232 del Reglamento de Organización, Funcionamiento y Régimen jurídico de las Corporaciones locales de 17 de mayo de 1952.

b) Porque el ejercicio de acciones es abligatoria para las Corporaciones, en virtud del artículo 370 de la Ley de Régimen local y del. artículo 338 del Reglamento de Organización, Funcionamiento y Régimen jurídico de las Corporaciones locales, según el cual éstas «tienen el deber inexcusable de defender sus bienes y derechos mediante el ejercicio de las pertinentes acciones y previo dictamen de un Letrado».

Este deber inexcusable disminuye la problemática del Secretario-Letrado que haya de dictaminar.

c) No existe fundamento para considerar que el ejercicio por una Corporación local de determinadas acciones (por ejemplo, en un juicio 
de arrendamiento urbano por un local arrendado para una escuela, o un recurso contencioso-administrativo contra una resolución ministerial en la clasificación o retribución de una plaza de ordenanza en su plantilla de funcionarios) tenga tal relevancia que exija, en todo caso, el dictamen de Letrado distinto al del Secretario de la Corporación. Por el contrario, la resolución de un expediente administrativo de una compleja concesión de un servicio municipal, por ejemplo, de alcance económico de varios millones de pesetas, no exige el dictamen de Letrado alguno.

(di) El prestigio y competencia del Secretario-Letrado dc la Corporación local parecen pospuestos con esta exigencia del dictamen de Letrado, no Secretario. Es aquel funcionario quien ha vivido las vicisitudes de cada caso y expediente y, por tanto, quien posee los mejores elementos de juicio para emitir dictamen sobre la procedencia de ejercitar acciones judiciales. De hecho, además, resulta que, en no pocos casos, el dictamen de Letrado que exige la Ley se cumple solamente en su aspecto formal. Las cartas principales se reservan para el pleito, en el proceso propiamente dicho, donde se agota la cuestión de Derecho, entrando en el fondo del problema.

Conviene una aclaración, si bien resulta obvia. No descartamos la conveniencia del dictamen de Letrado en el caso de ejercicio de acciones, como contraste de opiniones, de gran utilidad para el Secretario y la Corporación.

A lo que mostramos nuestra disconformidad es a que dicho dictamen de Letrado se exija preceptiva y obligatoriamente bajo pena de excepción procesal. Donde realmente son necesarios los servicios de Letrado-Abogado es en el proceso, por la incompatibilidad o imposibilidad práctica del Secretario-Letrado, cuyas funciones son ya suficientemente complejas, y porque en el pleito es donde se requiere ya la experiencia y técnica que proporciona el ejercicio de la Abogacía.

\section{CONCLUSION}

Para finalizar exponemos a continuación la redacción que nosotros daríamos a los preceptos básicos relativos al dictamen de Letrado previo al ejercicio de acciones, recogiendo las ideas y criterios anteriormente expuestos:

Artículo 370 de la Ley de Régimen local: «Las Corporaciones locales tienen la obligación de ejercer las acciones necesarias para la defensa de sus bienes y derechos. El acuerdo para el ejercicio de acciones judiciales ante los Tribunales de las distintas jurisdicciones deberá ir precedido del dictamen de un Letrado, que será el del Secretario de la Corporación cuando fuere Licenciado en Derecho».

Articulo 338 del Reglamento de Organización, Funcionamiento y Régimen juridico de las Corparaciones locales: «1. Las Corporaciones locales tienen la obligación de ejercer las acciones necesarias para la de- 
fensa de sus bienes y derechos. El acuerdo para el ejercicio de acciones judiciales ante los Tribunales de las distintas jurisdicciones deberá ir precedido del dictamen de un Letrado, que será el del Secretario de la Corporación cuando fuere Licenciado en Derecho.

2. Cuando el dictamen fuere opuesto al ejercicio de la acción, podrán recabarse otros o renunciar a entablarlos, y en cualquier caso, promoverla sin someterse a ninguno de ellos.

3. Aparte de los informes jurídicos que emita el Secretario, los Letrados asesores de la Corporación pertenecientes a su plantilla de funcionarios tendrán la obligación de informar, ateniéndose a lo previsto en el artículo 286.

4. Si la Corporación no tuviere Letrados podrá solicitar el dictamen de Abogado que figure inscrito en el Colegio correspondiente». 